\title{
Review on Operation Management Mode of Urban Underground Utility Tunnel
}

\author{
Huixuan Liu ${ }^{1,2, *}$, Dongfu Zhao ${ }^{1,2}$, Guohua Li ${ }^{1,2}$, Jun Dong ${ }^{1,2}$ \\ ${ }^{1}$ Beijing Advanced Innovation Center for Future Urban Design, Beijing, China. \\ ${ }^{2}$ School of Civil and Transportation Engineering, Beijing University of Civil Engineering and \\ Architecture, Beijing, China. \\ *mushroom0620@163.com
}

\begin{abstract}
This paper reviews the origin and development of urban underground utility tunnel at home and abroad through literature review, analyzes the research status of the operation management mode of urban underground utility tunnel at home and abroad, and probes into the problems to be solved in the current operation management mode of urban underground utility tunnel and the followup research direction.
\end{abstract}

Keywords: literature review; research status; operation management.

\section{Introduction}

As a city's transportation network, urban roads are not only burdened with heavy ground traffic, but also provide urban green space and evacuation sites during earthquake emergency [1]. The various pipelines that are necessary for the public, such as tap water, gas, electricity, communications, cable TV, rainwater and sewage systems, are all buried under the road. Because the pipeline is laid by direct burial, it is not only easy to cause repeated excavation of roads, but also easy to cause pipeline safety accidents. Therefore, in foreign developed countries, integrated pipeline corridors are gradually used for pipeline laying.

The so-called integrated pipe corridor is the "underground city pipeline integrated corridor", that is, constructing a tunnel space underground in the city, integrating various pipelines such as municipal, electric power, communication, gas, water supply and drainage, etc., with special inspection, hoisting port and monitoring system, which was unified planed, unified designed, unified constructed and managed. Integrated pipe corridors have different names in different countries and regions. In Japan, the integrated pipe corridor is called the "common ditch", and the integrated pipe gallery in Taiwan Province of China has become a "common channel". Mainland China is called "integrated pipe gallery", "common ditch" or "integrated pipe ditch" [2].

\section{Research Status of Management Model of Foreign Operation Management Mode of Urban Underground Utility Tunnel}

Since 1833, Paris has begun to build the world's first underground pipeline integrated pipe gallery. The development of the integrated pipe gallery has been more than 180 years old. After more than 100 years of exploration, research, improvement and practice, the technology of urban underground integrated pipe corridors has been basically mature. At present, France, the United Kingdom, Germany, Spain, Russia, Sweden, Finland and other countries have a large-scale integrated corridor. So far, Japan is one of the countries with the most advanced underground technology, the most complete regulations, the most complete planning and the fastest construction.

According to statistics, Japan planned to build a comprehensive pipe gallery of about $1100 \mathrm{~km}$ by the beginning of the 21 st century. By 2001, a comprehensive pipe gallery of more than $600 \mathrm{~km}$ had been built [3]. The outstanding experience of Japan's integrated pipe gallery construction can be summarized into three points. First, legislation has priority. For example, it is stipulated that the excavation of the integrated pipe corridor section, the property rights of the integrated pipe gallery and the paid use of the underground space are provided; the second is the overall planning. Integrate the integrated pipe gallery with underground projects such as subways and underground complexes 
into urban underground space planning, and form a common and integrated development, which has become one of the characteristics of underground space utilization in Japan, and has been continuously developed to the underground space; the third is certify a clear management department, unified management and operation [4].

Developed countries such as Europe have strong financial capacity, and utility tunnel are treated as public goods. Construction investment is basically funded by the government. After completion, property rights are owned by the government [5]. In the later operation, the government allowed the pipeline to enter the gallery by collecting the rent of the pipeline unit. However, there is no clear provision on the amount of rent collected, and the amount of rent is not completely fixed, but is determined annually by the parliamentary hearing of the location of the corridor. This form is generally guaranteed by a relatively complete legal system. Through legal procedures and administrative constraints, pipeline units must use public corridors and provide guarantees for later operations [6].

The construction of advanced national integrated pipe corridors generally shows the characteristics of systematic and standardized planning and design, perfect engineering technology, continuous improvement of laws and regulations, and innovation of operation and maintenance corridors [7]. Mainly reflected in the following four aspects: First, the government attaches great importance to it, the management mechanism system is clear, laws and regulations, standards and norms form an institutional system; second, give full play to the leading role of planning and design, according to the overall situation of urban development and urban overall planning needs, Overall planning and intensive use; Third, in terms of technology, to achieve a variety of pipelines into the corridor: in addition to radio and television, communications, electricity, industry, water supply and drainage, gas, heat and other pipelines, but also based on the pipeline characteristics of innovative laying methods, the development of reclaimed water, garbage Special collections such as vacuum collection and district energy supply pipelines; the fourth is the continuous innovation of the life cycle operation and management model of the management corridor.

\section{Research Status of Domestic Utility Tunnel Operation and Maintenance Management Mode}

From June 14, 2014, the General Office of the State Council issued the "Guiding Opinions on Strengthening the Management of Urban Underground Pipeline Construction". On August 3, 2015, the General Office of the State Council issued the "Guiding Opinions on Promoting the Construction of Urban Underground Integrated Pipe Gallery". The promotion and support of the city's comprehensive management corridor in the national policy layer is constantly increasing [8]. However, the relevant domestic norms are still not perfect, and in practice they are based on foreign technology. What's more, due to differences in pipeline characteristics, construction technology, material properties and geological conditions, it is necessary to study and formulate relevant design specifications in accordance with the current characteristics of China to realize the comprehensive underground corridors in China [9]. Establish a specialized integrated management system for management of corridors, and reasonably share the relevant costs of integrated corridors [10].

Some scholars have perfected the management system by establishing various evaluation theories and models. In 2014, the State Council proposed "actively promoting the marketization of municipal infrastructure investment operations and improving the government and social capital cooperation (PPP) mechanism", and encouraged social capital to participate in infrastructure construction. Local governments and relevant departments have begun to actively explore and practice the PPP model. The UK was the first to apply the VFM evaluation method to the feasibility evaluation of the project under the PPP/PFI model. In the process of continuous exploration, the government issued the "VFM Evaluation Guide", which formed a relatively standardized VFM evaluation system. In addition, Germany, Japan, Canada, France, Singapore, the United States, Hong Kong and other regions are also studying the UK, constantly improving the evaluation mechanism of government and social capital cooperation [11]. Domestic scholar Shen Yuyu [12] proposed the quantitative calculation 
method of VFM evaluation method under the background of foreign mature theory and practice, and simply divided the PFI project into government-purchased service-oriented projects and profitoriented projects, using present value and net respectively. The present value method estimates the results, but does not cover the actual application part. Liu Huihui scholar [13] briefly studied the VFM evaluation theory through literature review, analyzed and selected the VFM evaluation calculation method, established the VFM evaluation model with the integrated pipe corridor project, and verified the VFM evaluation PPP mode integrated pipe gallery through practical engineering. The feasibility of the project.

Some scholars also pay attention to solving the complexity of the operation and maintenance of integrated pipe corridors. Integrated management of the corridor is a systematic and complex project. On the one hand, because the integrated pipe gallery is built underground, only a small number of feeding ports, personnel entrances and exits and vents are connected to the outside world. In the actual operation process, safety blind spots may be generated, and even a security blind zone may be formed, which becomes an accident-prone zone; the space of the integrated pipe gallery is relatively sealed. In the case that the warning notice cannot be issued in time and effectively, the time for evacuation and escape will become very limited [13]. The above reasons will not only cause damage to the facilities and equipment in the integrated pipe gallery, but also cause catastrophic consequences such as casualties. Zheng Lining et al. [7, 14, 15] proposed that the current urban integrated pipe corridor monitoring system has low reliability and poor interactivity, and proposed to use cloud computing technology to construct an integrated pipe corridor operation management system. Bai Hailong [8] proposed to integrate the integrated pipe gallery and underground space construction, combine the design of the integrated pipe gallery with the technical measures of the sponge city, and use the "BIM+GIS" technology to model the engineering information and provide digital and visualized The engineering method greatly facilitates the intelligence of the later operation management and realizes the safety, reliability and convenience of the integrated pipe corridor operation.

\section{Conclusion}

At present, China has not yet enacted legislation on the construction of integrated pipe corridors from the national level. The regulations of local governments on underground space ownership, pipeline access, cost sharing, management departments and management fees are uneven. The construction of integrated pipe corridors mainly depends on National policy encouragement and government administrative constraints have been promoted [4], and administratively binding rules and regulations have not been formed. Therefore, the formation of a management system suitable for the operation of integrated corridors, and the establishment of an intelligent operation management model based on the unified evaluation theory and model will be the main research direction of the underground integrated pipeline operation and maintenance model in the future.

\section{Acknowledgments}

The present work was supported by the National Natural Science Foundation of China (No. 51378045), the BUCEA Post Graduate Innovation Project (No. PG2018029), the Open Research Fund Program of Engineering Structure and New Materials of Beijing University Engineering Research Center (Beijing University of Civil Engineering and Architecture), Beijing Advanced Innovation Center for Future Urban Design, summer job camp in Japan and the Beijing Collaborative Innovation Center of Energy Conservation and Emissions Reduction Technology. The authors gratefully acknowledge the mentioned support. 


\section{References}

[1]. Y. Wang, L.J. Wang, Z.Y. He, T.B. Ling, L. Lang. Empirical Study on Driving Force of Urban Utility Tunnel Development, Chinese Journal of Underground Space and Engineering. 13 (2017) 1444-1451.

[2]. X.L. Xiong, H.X. Liu, Y.R. Cen. Discussion on the construction of urban underground comprehensive pipe gallery, Urban Geotechnical Investigation \& Surveying. 2 (2016) 148-150.

[3]. Q.F. Jiang, G.H. Zhu. A brief discussion on the urban common ditch, Nonferrous Metals Engineering \& Research. 22 (2001) 46-53.

[4]. Z.S. Tan, X.Y. Chen, X.Y. Wang, M.L. Huang. Construction management model and key technologies for underground utility tunnels in urban areas, Tunnel Construction. 36 (2016) 1177-1188.

[5]. J.J. Zhang. Analysis of Operation Management Mechanism of Urban Underground Utility Tunnel, China Municipal Engineering. 197 (2018) 54-57.

[6]. W.H. Li. Analysis on the problems and countermeasures of the construction of urban underground comprehensive pipeline trench, The Urban Construction Archives Magazine. 6 (2011) 65-66.

[7]. L.N. Zhen, J. Wang, C.Y. Luo. Construction of urban integrated pipe corridor operation management system, Construction Economy. 37 (2016) 92-98.

[8]. H.L. Bai. A trend study of urban common tunnel development, China Municipal Engineering. $182(2015) 78-81$.

[9]. C.L. Yu, Z.H. Zhang. Development history and current situation of urban underground comprehensive pipe gallery at home and abroad, Construction Science and Technology. 17 (2005) 49-51.

[10]. Z.C. Zhang, H.P. Jiang, Q.Q. Shi. Analysis on the trend of multi-country integrated pipe gallery construction, Urban and Rural Development. 1 (2018) 72-75.

[11]. D. Song. Research on the operations management of tube gallery based on PPP model, PhD Thesis, Beijing: Beijing University of Civil Engineering and Architecture. 2014.

[12]. Y.Y. Shen, J. Du. Analysis of the value of funds in public projects using private active financing models, Construction Management Modernization. 22 (2008) 53-55.

[13]. H.H. Liu, J. Sun, F.F. Li. VFM evaluation of PPP mode applied to urban underground integrated pipe gallery, Journal of Civil Engineering and Management. 33 (2016) 122-126.

[14]. J. Jiao. Application of PPP in integrated pipe gallery, China Concrete. 4 (2016) 14-17.

[15]. J.X. Zhang, H.Y. Li, M. Cai. Municipal infrastructure construction of underground public space in the core area of Beijing CBD, Construction Technology. 45 (2016) 99-104. 